Category by field: Plant Science $>$ Plant biochemistry $>$ Other compound

Category by field: Biochemistry > Other compound > Triterpene

3 Category by organism: Plants $>$ General $>$ Whole plant $>$ Other compound

4

5

\section{Isolation of Triterpenes from Propolis (Bee Glue)}

Muhammad N. Kardar ${ }^{1}$ and Veronique Seidel ${ }^{1 *}$

${ }^{1}$ Strathclyde Institute of Pharmacy and Biomedical Sciences, University of Strathclyde, Glasgow G4 ORE, Scotland, UK

*For correspondence: veronique.seidel@strath.ac.uk .

[Abstract] Propolis (bee glue) is a natural substance produced by bees upon collection of mainly plant resins. Bees use it as antiseptic sealing agent between honeycombs and to preserve the hive from external contamination. Numerous scientific studies have been published on the biological properties of propolis including its anti-inflammatory, anti-oxidant, immunostimulant, antitumour and antimicrobial activity. Different propolis chemotypes have been characterised based on the nature of the plant-derived substances present and the geographical origin of collection. Here, we describe the isolation of nine triterpenes from a sample of propolis originating from North-Western Cameroon. All compounds were identified following analysis of their spectroscopic data and comparison with previously published reports.

\section{Materials and Reagents}

1. Raw propolis (Nature's Laboratory Ltd, code number: P5)

2. Ethanol $96 \% \mathrm{v} / \mathrm{v}$ (extra pure, Specified Laboratory Reagent) (Fisher, Scientific, catalog number: 10162252)

3. Hexanes (for HPLC, 95\% $n$-hexane approx.) (Fisher Scientific, catalog number: 10703611)

4. Ethyl acetate, extra pure, Specified Laboratory Reagent (Fisher Scientific, catalog number: 10080130)

5. Sodium sulfate anhydrous, extra pure (Fisher Scientific, catalog number: 10606082)

6. TLC silica gel 60 F254 plates (VWR International Ltd, catalog number: 1.05554.0001)

7. Silica gel $60(0.063-0.200 \mathrm{~mm})$ (VWR International Ltd, catalog number: 1.07734 .1000$)$

8. Silica gel $60 \mathrm{H}$ (VWR International Ltd, catalog number: 1.07736.1000)

9. $98 \%$ p-Anisaldehyde (Sigma-Aldrich, catalog number: A88107)

10. Sulfuric acid (pure) (Fisher Scientific, catalog number: 10222282)

11. Acetic acid glacial (pure) (Fisher Scientific, catalog number: 10375020)

12. Methanol (extra pure, Specified Laboratory Reagent) (Fisher Scientific, catalog number: 10214490) 
13. Sephadex ${ }^{\circledR}$ LH-20 (Sigma-Aldrich, catalog number: LH20100)

14. $\alpha$-amyrin (Sigma-Aldrich, catalog number: 53017)

15. Cycloartenol (Sigma-Aldrich, catalog number: 08172)

16. Lupeol (Sigma-Aldrich, catalog number: S957712)

17. Dichloromethane, extra pure, stabilised with amylene, Specified Laboratory Reagent (Fisher Scientific, catalog number: 10458210)

18. Chloroform-d $\left(\mathrm{CDCl}_{3}\right)$ (Sigma-Aldrich, catalog number: 10080130)

19. Anisaldehyde-sulphuric acid reagent (see Recipes)

\section{Equipment}

1. Heated ultrasonic water bath (Fisher Scientific, catalog number: 10215332,340 W)

2. Büchi rotary evaporator, Rotavapor ${ }^{\circledR}$ R-210 (VWR International Ltd, catalog number: 5310850)

3. UV viewing cabinet CC10 (Fisher Scientific, catalog number: 11778201)

4. UV lamp UVG-11 230V 50/60Hz $4 \mathrm{~W}$ hand held short wave (Fisher Scientific, catalog number: 11718241)

5. UV lamp UVL-21 $230 \mathrm{~V} 50 / 60 \mathrm{~Hz} 4 \mathrm{~W}$ hand held long wave (Fisher Scientific, catalog number: 11728241)

6. Analytical balance (VWR International Ltd, catalog number: 611-2267)

7. Precision balance (VWR International Ltd, catalog number: 611-2695)

8. Vacuum water jet pump (VWR International Ltd, catalog number: 181-9100)

9. Pear-shaped (separating) funnel, $1000 \mathrm{ml}$ (Scientific Glass Laboratories, catalog number: SFP1L)

10. Round bottom flasks, $250 \mathrm{~mL}$ (Total number of 12 ). (Scientific Glass Laboratories, catalog number: FRS250/B19 or FRS250/B24)

11. Glass foot measuring cylinder with hexagonal base, borosilicate glass, class "B", $25 \mathrm{~mL}$ and $250 \mathrm{~mL}$ (Scientific Glass Laboratories, catalog number MCB/25 and MCB/250)

12. Conical Erlenmeyer flasks, $500 \mathrm{ml}$ (Scientific Glass Laboratories, catalog number: FC500/B24)

13. Filter funnels, borosilicate (Scientific Glass Laboratories, catalog number: BFF75 and BFF100)

14. Rubber vacuum tubing NW8 (VWR international Ltd, catalog number: 189.3111)

15. Glass Pasteur pipettes $150 \mathrm{~mm}$ (Fisher Scientific, catalog number: 10006021)

16. Glass Pasteur pipettes $230 \mathrm{~mm}$ (Fisher Scientific, catalog number: 10209381)

17. Glass micropipettes (homemade from glass Pasteur pipettes $230 \mathrm{~mm}$ using a Bunsen burner)

18. Büchner filter with cone and thread, GL14, for vacuum liquid chromatography (VLC) (Scientific Glass Laboratories, catalog number TBF/4/B24/POR3)

19. Twin trough chambers for TLC plates (VWR International Ltd, catalog number:552-0011)

20. Glass atomiser reagent sprayer (VWR International Ltd, catalog number: 552-0031) 
21. Wilmad ${ }^{\circledR}$ NMR tubes $5 \mathrm{~mm}$ diam., precision (Sigma-Aldrich, catalog number: Z274275)

22. Glass chromatography columns (CC) with sintered discs (Scientific Glass Laboratories, catalog number: R2/40)

23. Snap-cap vials (VWR International Ltd, catalog number 548-0555)

24. Duratool DO1600 hot air heat gun (from www.amazon.co.uk)

25. Whatman qualitative filter paper, grade 1 (Sigma-Aldrich, catalog number WHA1001125)

26. Exactive Orbitrap mass spectrometer (MS) operating in a positive and negative electrospray ionisation (ESI) switching mode (Thermo Scientific, UK)

27. JEOL 505HA high resolution electron impact (HREI) mass spectrometer (MS) using direct probe at elevated temperature $\left(110 \sim 160^{\circ} \mathrm{C}\right)$ at $70 \mathrm{eV}$

28. Xcalibur software (version 2.2) for MS data processing (Thermo Scientific, UK)

29. JEOL Lambda Delta 400 NMR spectrometer (JEOL Ltd)

30. Mestre Nova (MNova) software (version 8.0.0) for NMR processing (Mestrelab Research SL, Spain)

\section{Procedure}

1. The whole procedure described below takes around 6 weeks to complete. All steps are done at room temperature $\left(20-25{ }^{\circ} \mathrm{C}\right)$ unless otherwise stated. Weigh propolis (ca. $50 \mathrm{~g}$ ) in a conical Erlenmeyer flask then add $70 \%$ ethanol in water $(500 \mathrm{~mL})$ to the flask.

2. Place the flask in the ultrasonic water bath on high for $1 \mathrm{~h}$ at $60^{\circ} \mathrm{C}$.

3. Recover the supernatant into a second conical Erlenmeyer flask and re-extract the raw material left-over in the original flask using fresh $70 \%$ ethanol $(500 \mathrm{~mL})$ as in step 2. Repeat this process 10 times and combine all supernatants.

4. Filter the pooled supernatants into a round-bottom flask using a glass filter funnel overlaid with filter paper. Discard the insoluble material (brown solid) remaining on the filter paper. The filtered extract is a clear amber solution. Keep this filtered extract in a fridge at $4{ }^{\circ} \mathrm{C}$.

5. Concentrate the filtered extract in the round-bottom flask to dryness under reduced pressure at $\leq 40{ }^{\circ} \mathrm{C}$ using a rotary evaporator. To achieve this, adjust the water bath to $60{ }^{\circ} \mathrm{C}$ and apply a vacuum of $175 \mathrm{mbar}$. Complete evaporation will occur in around $30 \mathrm{~min}$.

6. Add distilled water $(250 \mathrm{~mL})$ and pure $(96 \%)$ ethanol $(25 \mathrm{~mL})$ to the dried extract to obtain a suspension.

7. Place a separating funnel onto a metallic stand (Fig 1), close its stopcock and slowly pour the suspension into the separating funnel.

8. Add hexane $(250 \mathrm{~mL})$ to the separating funnel,

9. Hand-shake the funnel gently several times. Remove the top stopper, then allow for the solvents to settle until into two immiscible phases. Recover the aqueous phase (bottom layer) and the hexane phase (top layer) in separate Erlenmeyer flasks. Do this by slowly opening the stopcock and closing it just before the curved meniscus between the two liquids reaches the stopcock. 
10. Place the aqueous phase back inside the separating funnel.

11. Repeat steps 8 and 10 twice using fresh hexane.

12. Add ethyl acetate $(250 \mathrm{~mL})$ to the funnel and repeat step 9 to 10 (the aqueous phase is the bottom layer and the ethyl acetate phase is the top layer).

13. Repeat step 12 twice using fresh ethyl acetate.

14. Sprinkle some sodium anhydrous sulfate into the recovered hexane and the ethyl acetate phases and gently manually rotate the Erlenmeyer flasks to observe if the cloudiness (i.e. residual water droplets) disappears. Continue sprinkling sodium sulphate and rotating the flasks until the liquids are completely clear.

15. Filter each organic phase into a round-bottom flask using a glass filter funnel overlaid with filter paper. Discard the insoluble material (sodium sulfate) remaining on the filter paper. The filtered extracts are clear solutions; concentrate them to dryness under reduced pressure at $\leq 40^{\circ} \mathrm{C}$ using a rotary evaporator. To achieve this, adjust the water bath to $60^{\circ} \mathrm{C}$ and apply a vacuum of $335 \mathrm{mbar}$ (hexane) or $240 \mathrm{mbar}$ (ethyl acetate). Complete evaporation will occur in around 20 min.

16. Store the hexane and the ethyl acetate extracts at $-20^{\circ} \mathrm{C}$.

17. Dissolve a portion ( 5 to $10 \mathrm{~g}$ ) of the hexane extract in $10 \mathrm{~mL}$ of a suitable solvent (e.g. dichloromethane, ethyl acetate and/or hexane) and mix with silica gel 60 (3 g). Leave the mixture to dry on a bench at $20-25^{\circ} \mathrm{C}$. A free-flowing and completely dried powder is usually obtained overnight.

18. Connect the Büchner filter for VLC to a vacuum water jet pump and pack it with silica gel $60 \mathrm{H}$. Leave a space $(\mathrm{ca} .3 \mathrm{~cm}$ ) above the compacted layer of silica layer so as to accommodate the sample and an appropriate volume of solvent. Allow hexane to pass through the column under vacuum to check the uniformity of the column.

19. Slowly and uniformly spread the powder prepared in step 17 as a thin layer (ca, $1 \mathrm{~cm}$ ) directly on to the top of the packed VLC column. Carry out the elution with hexane-ethyl acetate mixtures of increasing polarity (starting with 100\% hexane, hexane/ethyl acetate 95:5, 9:1, $85: 15,8: 2,7: 3,6: 4,1: 1,4: 6,25: 75,3: 7,2: 8,1: 9$ and lastly 100\% ethyl acetate). Add a defined volume of solvent (ca. $300 \mathrm{~mL}$ ) to the top of the VLC column each time and apply vacuum until the column dries up (Fig. 2) (Coll and Bowden, 1986; Pelletier et al., 1986). Collect each fraction in a round-bottomed flask and concentrate to dryness under reduced pressure at $\leq 40$ ${ }^{\circ} \mathrm{C}$ using a rotary evaporator. To achieve this, adjust the water bath to $60{ }^{\circ} \mathrm{C}$ and apply a vacuum of 240 mbar. Complete evaporation will occur in around 20 min.

20. Dissolve an aliquot of each fraction (ca.5-10 mg) in dichloromethane (ca.5 mL). Use a glass micropipette to apply 5-10 spots of each fraction as bands ca. $1 \mathrm{~cm}$ above the bottom edge of a thin layer chromatography (TLC) silica gel plate (Fig.3A).

21. Place a filter paper inside a TLC chamber and pour inside the chamber a mixture $(20 \mathrm{~mL})$ of hexane/ethyl acetate $(8: 2, \mathrm{v} / \mathrm{v})$. Leave the solvent in the chamber for $30 \mathrm{~min}$ at room temperature $\left(20^{\circ} \mathrm{C}-25^{\circ} \mathrm{C}\right)$ to help reach solvent saturation. Pour a mixture $(20 \mathrm{~mL})$ of hexane/ethyl acetate $(7: 3, \mathrm{v} / \mathrm{v})$ in second TLC chamber. Place the spotted TLC plates in the 
chambers and leave them to develop in an ascending direction until the solvent reaches ca. 1 $\mathrm{cm}$ below the top (Fig.3B).

22. Take the developed TLC plates out of the chambers and observe under UV light using short $(\lambda=254 \mathrm{~nm})$ and long $(\lambda=366 \mathrm{~nm})$ wavelengths. Spray anisaldehyde-sulphuric acid reagent (see Recipes) over the plates and heat the plates to $105-110^{\circ} \mathrm{C}$ with a heat gun for ca. $1 \mathrm{~min}$ until coloured spots appear (Fig.3C) (Waldi, 1965). Calculate Rf values for individual spots as the ratio of the distance (in $\mathrm{cm}$ ) from the centre of the spot to the baseline over the distance (in cm) from the solvent line to the baseline (Stahl and Mangold, 1975; Stock and Rice, 1974). Triterpenes typically appear as bright pink spots on TLC plates following spraying with anisaldehyde-sulfuric acid reagent and heating (Fig.3D).

23. The first pink coloured spot appears in the VLC fraction eluted with $15 \%$ ethyl acetate in hexane. Mix this fraction with silica gel $60(3 \mathrm{~g})$ in dichloromethane. Leave the mixture to dry on a bench at $20-25^{\circ} \mathrm{C}$. A free-flowing and completely dried powder is usually obtained overnight.

24. In a glass, beaker, mix enough silica gel 60 in hexane to obtain a slurry which has the right consistency so as to be poured to fill a CC glass column. Leave the column stopcock open when filling with the slurry to let the latter settle inside the column. Continue pouring the slurry inside the column until the silica particles settle and form a horizontal layer about $5 \mathrm{~cm}$ from the top of the column. Ensure that there is a sufficient volume (around $5 \mathrm{~mL}$ ) of solvent on top of the silica layer so the packing material does not dry out. Take care to prevent the inclusion of any air bubbles (Note 1) (Braithwaite and Smith, 1996; Ravindranath, 1989). Apply the powdered fraction to the top of the packed column.

25. Carry out the elution using hexane and ethyl acetate mixtures of increasing polarity (from $100 \%$ hexane, hexane/ethyl acetate 9:1, 8:2, 7:3, 6:4, 1:1, 4:6, 3:7, 2:8, 1:9 and lastly 100\% ethyl acetate) (Fig. 4). Collect all eluates in vials, and analyse their contents by TLC (step 2022).

26. One of the eluates appears as a single pink spot following spraying with anisaldehyde sulphuric acid reagent $(\mathrm{Rf}=0.40$ in hexane/ethyl acetate 8:2). Concentrate this eluate to dryness under reduced pressure at $\leq 40{ }^{\circ} \mathrm{C}$, dissolve it in chloroform-d $(2.5 \mathrm{~mL})$ and transfer it into an NMR tube. Carry out ${ }^{1} \mathrm{H},{ }^{13} \mathrm{C}$ NMR and MS analysis to reveal the presence of four triterpenes, namely $\alpha$-amyrin (Hernández Vázquez et al., 2012; Basyuni et al., 2006), $\beta$ amyrin (Basyuni et al., 2006; Mahato and Kundu, 1994), lupeol (Basyuni et al., 2006; Thanakijcharoenpath and Theanphong, 2007) and cycloartenol (Kamisako et al., 1987; Zhu et al., 2012).

27. Combine the VLC fractions eluted with $25 \%$ and $30 \%$ ethyl acetate in hexane, respectively. Concentrate them to dryness under reduced pressure at $\leq 40{ }^{\circ} \mathrm{C}$ using the rotary evaporator.

28. In a glass, beaker, mix enough Sephade ${ }^{\circledR}$ LH-20 (Note 2) in 5\% hexane in dichloromethane to obtain a slurry which has the right consistency so as to be poured to fill a CC glass column. Leave the column stopcock open when filling with the slurry to let the latter settle inside the column. Continue pouring the slurry inside the column until the Sephadex ${ }^{\circledR} \mathrm{LH}-20$ particles 
settle and form a horizontal layer about $5 \mathrm{~cm}$ from the top of the column. Ensure there is only the minimal volume of solvent remaining on the surface of the packing material so it does not dry out. Take care to prevent the inclusion of any air bubbles (Note 1). (Determann and Brewer, 1975; Kremmer and Boross, 1979).

29. Apply the combined fractions, re-dissolved in $5 \%$ hexane in dichloromethane, onto the top of the column.

30. Elute with $5 \%$ hexane in dichloromethane to afford an eluate which appears as a single pink spot on TLC following spraying with anisaldehyde-sulfuric acid reagent and heating $(R f=0.23$ in hexane/ethyl acetate 8:2). Concentrate this eluate to dryness under reduced pressure at $\leq$ $40{ }^{\circ} \mathrm{C}$, dissolve it in chloroform-d $(2.5 \mathrm{~mL})$ and transfer it into an NMR tube. Carry out ${ }^{1} \mathrm{H},{ }^{13} \mathrm{C}$ NMR and MS analysis to reveal the presence of two triterpenes, namely mangiferonic acid (Escobedo-Martinez et al., 2012), and ambonic acid (Da Silva et al., 2005).

31. Combine the VLC fractions eluted with $40 \%$ and $50 \%$ ethyl acetate in hexane, respectively. Concentrate them to dryness under reduced pressure at $\leq 40{ }^{\circ} \mathrm{C}$ using a rotary evaporator and subject them to gel filtration (see step 28).

32. Elute with $5 \%$ hexane in dichloromethane to afford one eluate containing a bright pink spot.

33. Fractionate this eluate further by CC (see step 24) using hexane/ethyl acetate mixtures of increasing polarity (from 100\% hexane, hexane/ethyl acetate 9:1, 8:2, 7:3, 6:4, 1:1, 4:6, 3:7, 2:8, $1: 9$ and lastly $100 \%$ ethyl acetate). One of the eluates appears as a single pink spot on TLC following spraying with anisaldehyde sulphuric acid reagent $(\mathrm{Rf}=0.40$ in hexane/ethyl acetate 7:3). Concentrate this eluate to dryness under reduced pressure at $\leq 40{ }^{\circ} \mathrm{C}$ using a rotary evaporator, dissolve it in chloroform- $\mathrm{d}(2.5 \mathrm{~mL})$ and transfer it into an NMR tube. Carry out ${ }^{1} \mathrm{H},{ }^{13} \mathrm{C}$ NMR and $\mathrm{MS}$ analysis to reveal the presence of two triterpenes, namely mangiferolic acid (Escobedo-Martinez et al., 2012) and ambolic acid (Escobedo-Martinez et al., 2012).

34. Subject a portion (5 to10 g) of the ethyl acetate extract to VLC eluting with hexane: ethyl acetate mixtures of increasing polarity (starting with 100\% hexane, hexane/ethyl acetate $95: 5,9: 1,85: 15,8: 2,7: 3,6: 4,1: 1,4: 6,3: 7,25: 75,2: 8,1: 9$ and lastly 100\% ethyl acetate) (step 13-15).

35. Fractionate the VLC fraction eluted with $40 \%$ ethyl acetate in hexane, by gel filtration (step 28) eluting with $5 \%$ hexane in dichloromethane, followed by dichloromethane, to yield a mixture of ambolic acid and isomangiferolic acid (Escobedo-Martinez et al., 2012) along with mangiferonic and mangiferolic acids as pure compounds.

\section{Representative data}


236

237

238

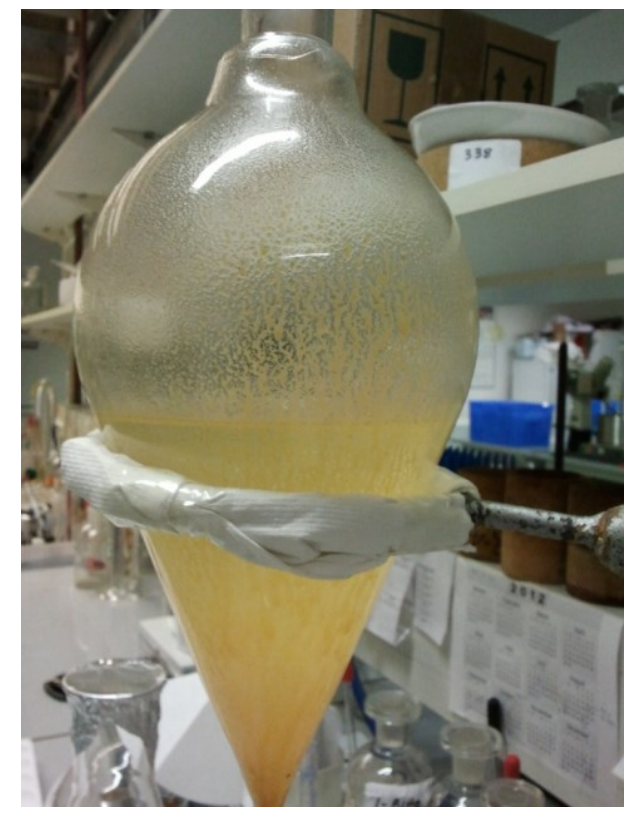

Fig.1. Typical set up for liquid-liquid partition using a separating funnel.

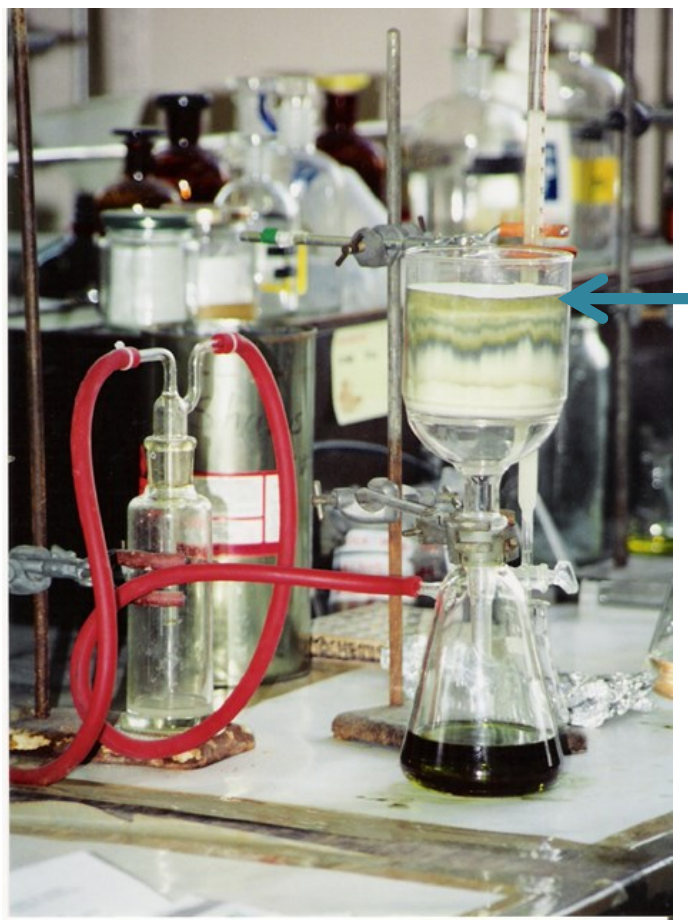

239

Fig.2. Typical set up for vacuum liquid chromatography (VLC)

241 


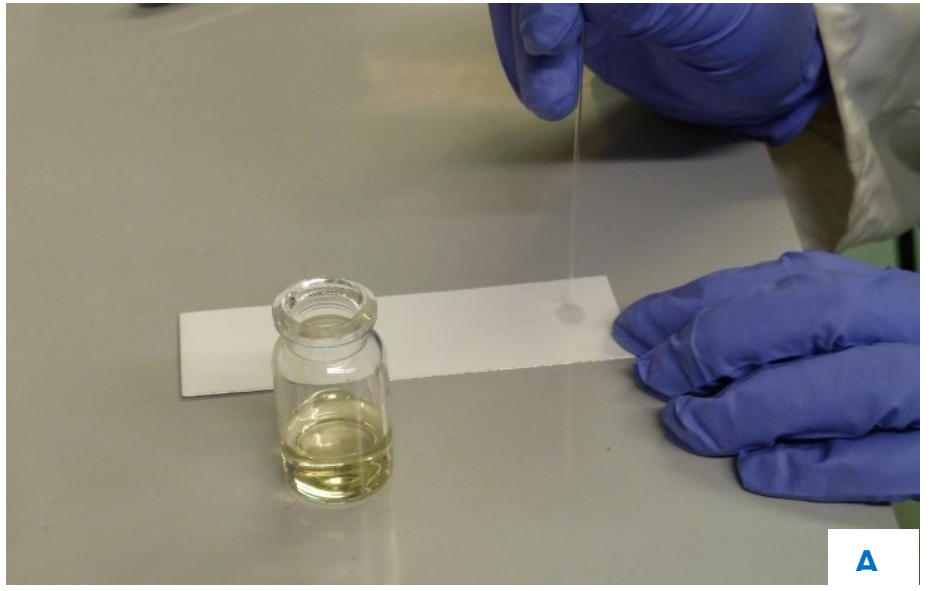

243

244

245

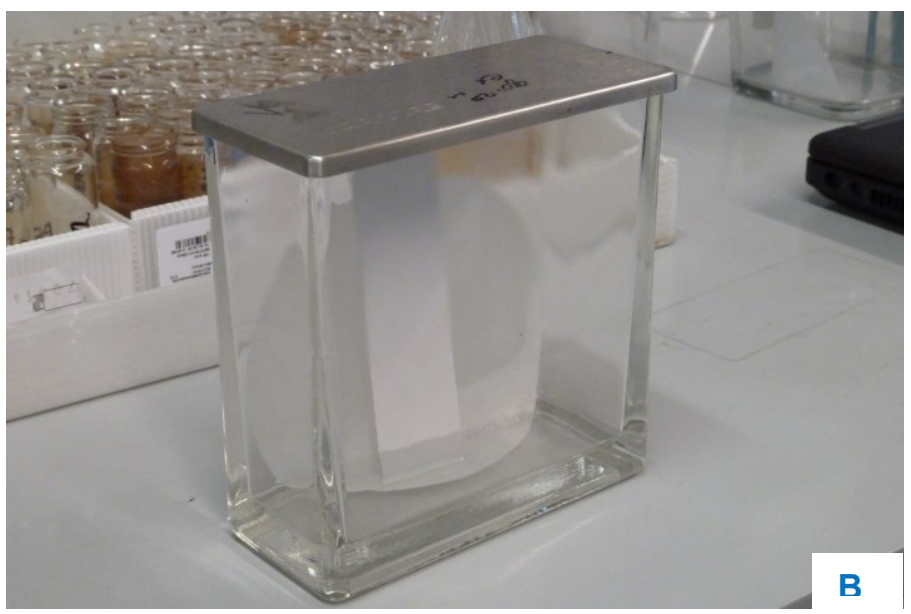

246

247

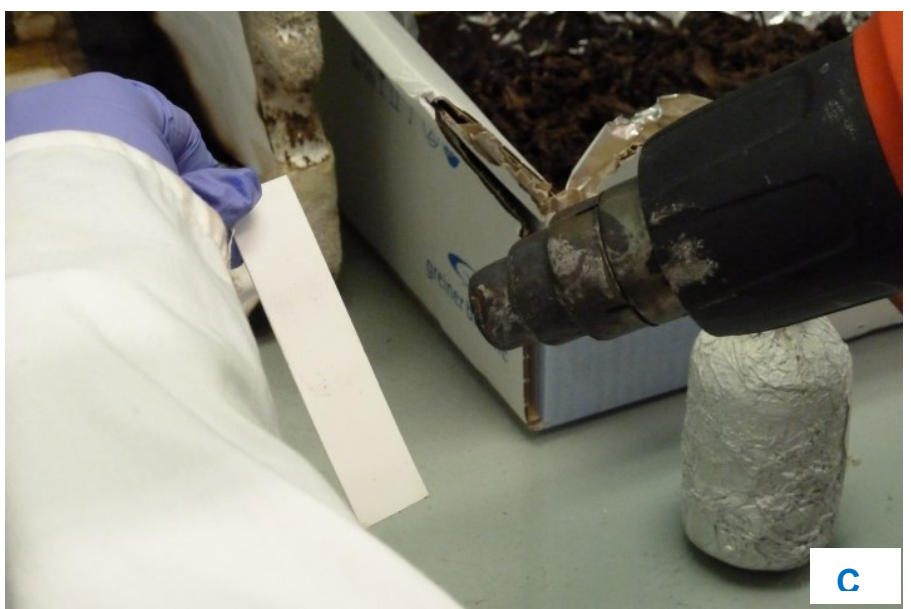

249

250 


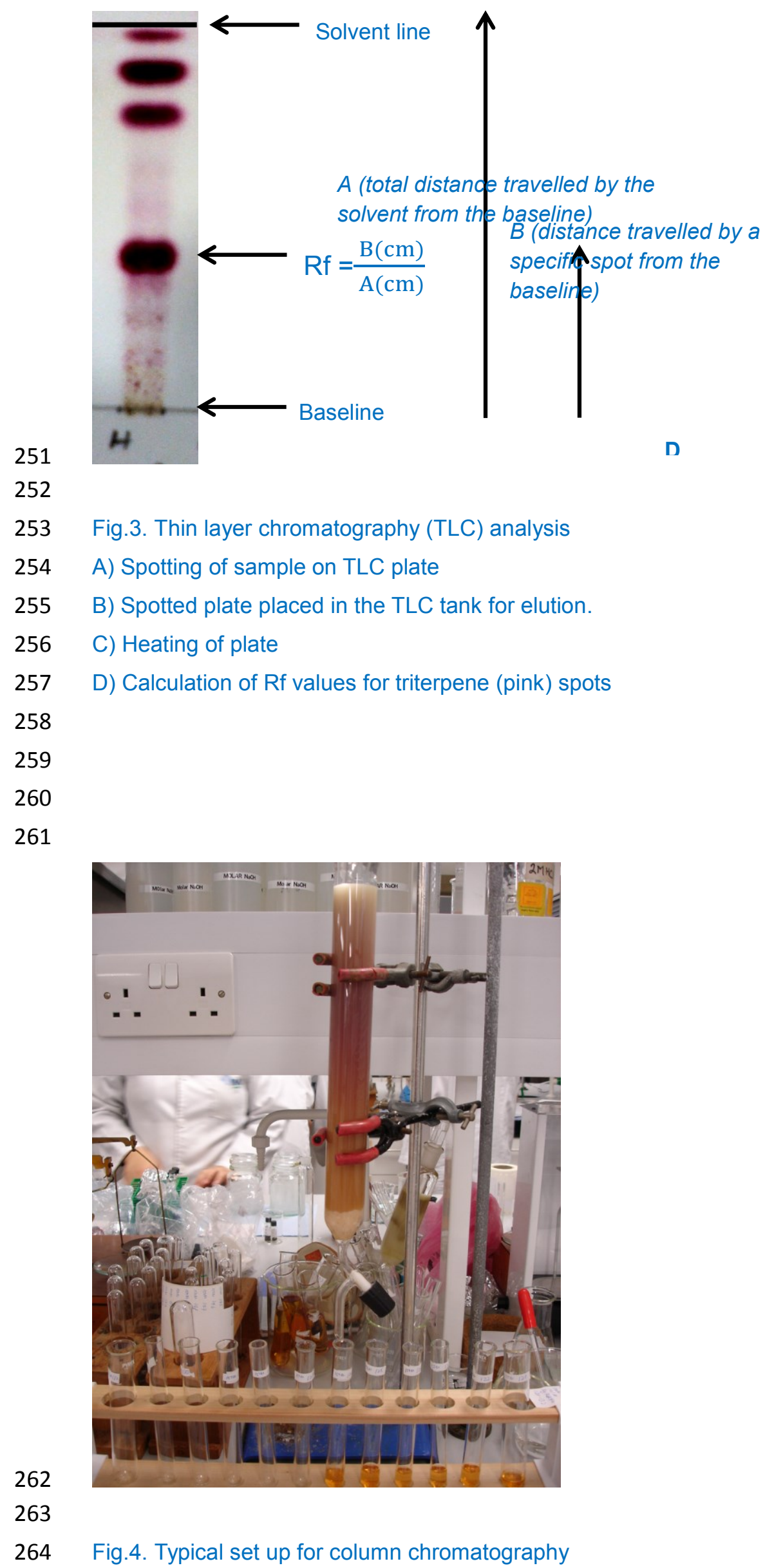




\section{Recipes}

\section{Acknowledgments}

283

\section{$\underline{\text { References }}$}

This protocol was adapted from the previously published study, Kardar et al. (2014). This work was supported by the Leverhulme Trust, UK (Research Project Grant RPG-150). We thank T. Zhang for technical assistance and Nature's Laboratory Ltd for the supply of propolis.

1. Basyuni, M., Oku, H., Inafuku, M., Baba, S., Iwasaki, H., Oshiro, K., Okabe, T., Shibuya, M. and Ebizuka, Y. (2006). Molecular cloning and functional expression of a multifunctional triterpene synthase cDNA from a mangrove species Kandelia candel (L.) Druce. Phytochemistry 67(23): 2517-2524.

2. Braithwaite, A. and Smith, F.J. (1996). Chromatographic methods. 5th edition. Blackie Academic and professional 117-64.

3. Coll, J. C. and Bowden, B. F. (1986). The application of vacuum liquid chromatography to the separation of terpene mixtures. J Nat Prod 49, 934-6.

4. Da Silva, M. S. S., Cito, A. M. G. L., Chaves, M. H., Lopes, J. A. D. (2005). Cycloartane triterpenoids of propolis from Teresina-PI. Quim Nova 28, 801-804.

5. Determann, H. and Brewer, J. E. (1975). Gel chromatography. In: Heftmann, E. (ed). Chromatography- A laboratory handbook of chromatographic and electrophoretic methods. Springer, 164-88. 
6. Escobedo-Martinez, C., Concepcion Lozada, M., Hernandez-Ortega, S., Villarreal, M. L., Gnecco, D., Enriquez, R. G. and Reynolds, W. (2012). (1) H and (13) C NMR characterization of new cycloartane triterpenes from Mangifera indica. Magn Reson Chem 50(1): 52-57.

7. Hernández Vázquez, L., Palazon, J., Navarro-Ocaña, A. (2012). The pentacyclic triterpenes $\square \square \square$-amyrins: a review of sources and biological activities. In: Rao, Venketeshwer (ed). Phytochemicals-a global perspective of their role in nutrition and health. In Tech Publisher.

8. Kamisako, W., Honda, C., Suwa, K. and Isoi, K. (1987). Studies of 13C NMR spectra of13Cenriched cycloartenol biosynthesized from [1-13C]-, [2-13C]- and [1,2,-13C2]-acetate. Revised 13C NMR spectral assignments of cycloartenol and cycloartanol and 13C NMR spectral support for the generally accepted skeleton formation mechanism of cycloartenol. Magn Res Chem 25, 683-687.

9. Kremmer, T. and Boross, L. (1979). Gel chromatography. Translated by Gabor, M. John Wiley and Sons. Budapest 17-31.

10. Mahato, S. B.and Kundu, A. P. (1994). ${ }^{13} \mathrm{C}$ NMR spectra of pentacyclic triterpenoids -a compilation and some salient features. Phytochemistry 37, 1517-1575.

11. Pelletier, S. W., Choksi, H. P. and Desai, H. K. (1986). Separation of diterpenoid alkaloid mixtures using vacuum liquid chromatography. J Nat Prod 49, 892-900.

12. Ravindranath, B. (1989). Principles and practice of chromatography. Ellis Harwood Ltd. 193292.

13. Stahl, E. and Mangold, H. K. (1975). Techniques of thin layer chromatography. In: Heftmann, E. (ed). Chromatography- A laboratory handbook of chromatographic and electrophoretic methods. Springer-Verlag, 164-88.

14. Stock, R. and Rice, C. B. (1974). Chromatographic methods. Chapman and Hall 279-317.

15. Thanakijcharoenpath, W. and Theanphong, O. (2007). Triterpenoids from the stem of Diospyros glandulosa. Thai J Pharm Sci 31, 1-8.

16. Waldi, D. (1965). Spray reagents for thin layer chromatography. In: Stahl, E. (ed). Thin layer chromatography A laboratory handbook. Springer, 483-502.

17. Zhu, Z. H., Liu, W. H., Ge, L. G., Yu, Q., Zhao, W. C., Yang, J. H. and Wan, H. T. (2012). Molecular cloning and characterization of a cDNA encoding cycloartenol synthase from Fritillaria thunbergii Miq. Afr J Biotechnol 11, 6896-6903. 